\title{
Uso do Radar no Desenvolvimento de Técnicas de Prospecção de Armadura em Estruturas de Concreto
}

\author{
Vicente Luiz Galli ${ }^{1}$, Daniel Mariani Guirardi ${ }^{2}$ \\ 1 Instituto de Pesquisas Tecnológicas, IPT - Seção de \\ Geotecnia \\ 2 Instituto de Pesquisas Tecnológicas, IPT - Seção de \\ Engenharia de Estruturas
}

Copyright 2014, SBGf - Sociedade Brasileira de Geofísica

Este texto foi preparado para a apresentação no VI Simpósio Brasileiro de Geofísica, Porto Alegre, 14 a 16 de outubro de 2014. Seu conteúdo foi revisado pelo Comitê Técnico do VI SimBGf, mas não necessariamente representa a opinião da SBGf ou de seus associados. É proibida a reprodução total ou parcial deste material para propósitos comerciais sem prévia autorização da SBGf.

\section{Resumo}

Este trabalho está focado na identificação de vergalhões de aço inseridos no concreto por meio do ensaio geofísico de radar. Os resultados obtidos mostraram que a posição do vergalhão pode ser projetada na superfície com precisão. É possível também comparar as bitolas dos vergalhões que estiverem a uma mesma profundidade por meio da análise de amplitude.

\section{Introdução}

Um grande número de pontes e viadutos de concreto tem necessitado de reparos e reforços devido a deterioração que tem sofrido ao longo do tempo. Durante este processo de recuperação, freqüentemente nos deparamos com a falta de projetos e plantas da localização exata das armaduras de aço e dos cabos de protensão para que reforços possam ser feitos.

O objetivo principal deste trabalho foi avaliar a técnica de prospecção de armadura de aço em concreto por meio da realização de ensaio não destrutivo com radar.

Os resultados obtidos mostraram que o radar pode ser uma boa opção na escolha entre as diferentes técnicas não destrutivas de investigação de armaduras de aço para os propósitos de reforço e recuperação de viadutos, pontes e estruturas de concreto, fornecendo informações precisas sobre a sua localização.

\section{Método}

O sistema de radar transmite pequenos pulsos de energia eletromagnética usando uma antena dipolar. As ondas EM se propagam através do material e são refletidas nas interfaces com propriedades dielétricas diferentes, como as interfaces entre concreto e vergalhão. As ondas direta $(\mathrm{Sd})$ e refletida $(\mathrm{Sr})$ são registradas pelo sistema como sinais de amplitude em função do tempo. A antena é deslocada na superfície da estrutura e um novo pulso é enviado, repetindo o processo e, assim, uma seção dos registros da posiçãotempo é gerada. A Figura 1 ilustra o esquema de obtenção dos dados do radar.

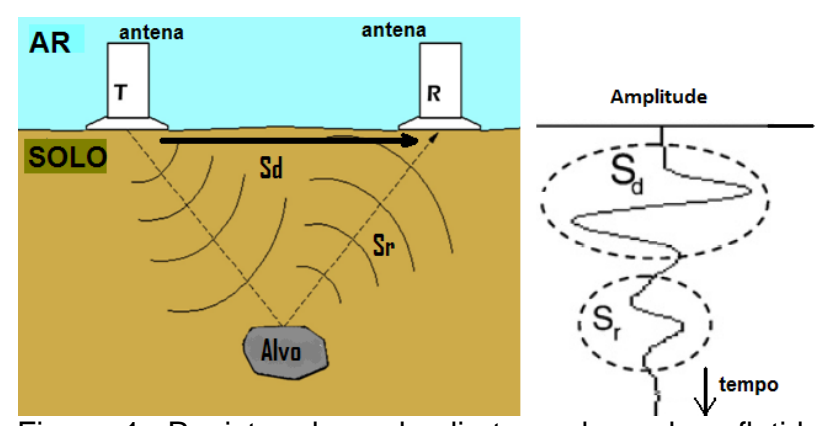

Figura 1. Registro da onda direta e da onda refletida obtido com o radar.

\section{Trabalhos realizados e resultados}

\section{a) Simulação teórica}

$\mathrm{Na}$ primeira etapa da pesquisa foi realizado um estudo teórico da anomalia a ser observada com o radar associada a vergalhões de aço de diferentes diâmetros colocados no concreto em profundidades variando entre 5 e $40 \mathrm{~cm}$ objetivando avaliar a possibilidade de se obter respostas diferentes.

Assim, utilizando-se o software GPRMAX2D (Giannopoulos, 2005), foram geradas algumas seções de radar do que deve ser observado quando 0 alvo investigado for um bloco de concreto contendo vergalhões de aço com diâmetros de 6.3, 8, 10, 10.5, 16, $20,25,32$ e $40 \mathrm{~mm}$, situados em várias profundidades.

As Figuras 2, 3 e 4 ilustram os resultados das seções de radar de algumas situações. 


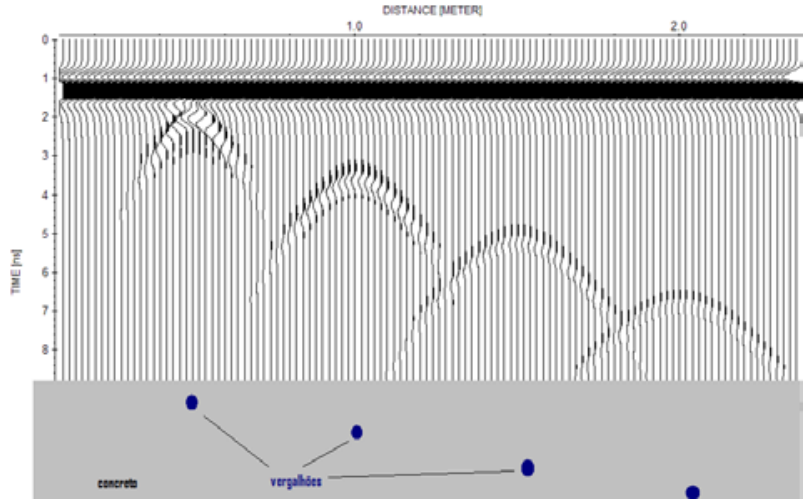

Figura 2. Seção de radar a ser observada na superfície de um bloco de concreto com quatro vergalhões iguais (6,3 mm de diâmetro) situados a 10, 20, 30 e $40 \mathrm{~cm}$ de profundidade.

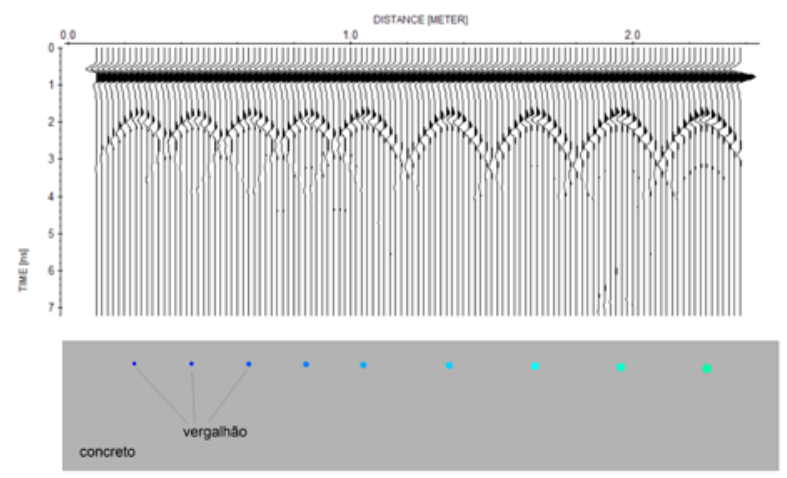

Figura 3. Seção de radar a ser observada na superfície de um bloco de concreto com nove vergalhões de diâmetros $6.3,8,10,10.5,16,20,25,32$ e $40 \mathrm{~mm}$ situados numa mesma profundidade.
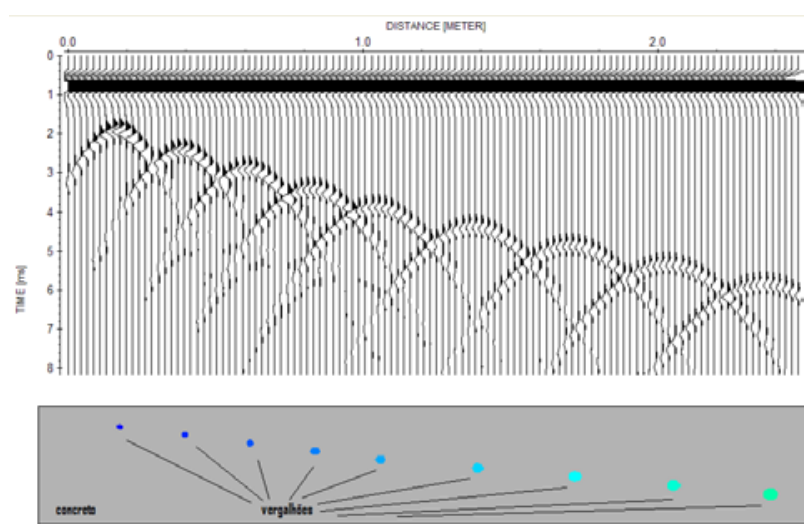

Figura 4. Seção de radar a ser observada na superfície de um bloco de concreto com nove vergalhões de diâmetros $6.3,8,10,10.5,16,20,25,32$ e $40 \mathrm{~mm}$ situados em diferentes profundidades.

As seções de radar geradas a partir dos modelos teóricos foram processadas com os programas RADPRO (Mala, 1995) e Reflex2DQuick (Sandmeier, 2008). Foram efetuados análise do espectro de potência e análise de amplitude. A Figura 5 mostra o resultado da análise de amplitude obtida para a seção de radar gerada para o bloco de concreto com nove vergalhões de diâmetros 6.3, $8,10,10.5,16,20,25,32$ e $40 \mathrm{~mm}$ situados numa mesma profundidade e a Figura 6 ilustra o resultado para o bloco de concreto com quatro vergalhões iguais $(6,3$ $\mathrm{mm}$ de diâmetro) situados a 10, 20, 30 e $40 \mathrm{~cm}$ de profundidade.

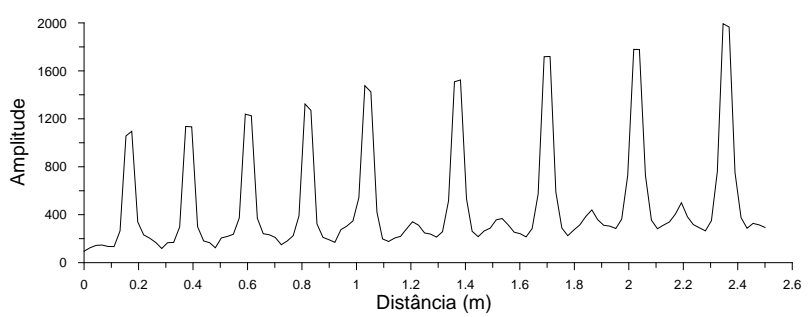

Figura 5. Gráfico da amplitude do sinal de radar da seção gerada para um bloco de concreto contendo nove vergalhões de diâmetros $6,3,8,10,10,5,16,20,25,32.0$ e $40 \mathrm{~mm}$ situados numa mesma profundidade.

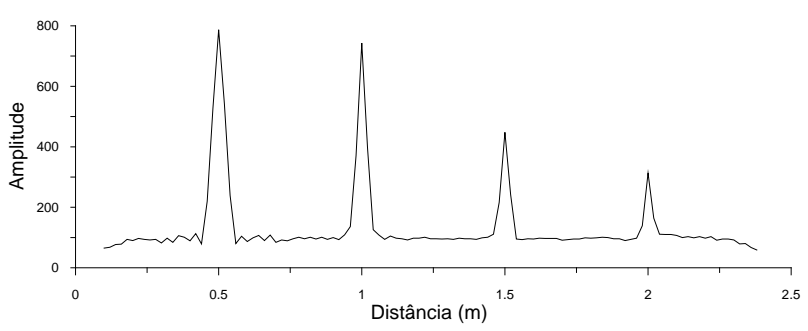

Figura 6. Gráfico da amplitude do sinal de radar da seção gerada para um bloco de concreto contendo quatro vergalhões iguais de $6.3 \mathrm{~mm}$ de diâmetro situados a 10, 20,30 e $40 \mathrm{~cm}$ de profundidade.

$\mathrm{Na}$ Figura 5, nota-se que a amplitude do sinal aumenta com o diâmetro do vergalhão para barras situadas a uma mesma profundidade e a Figura 6 mostra que a amplitude do sinal diminui com a profundidade do vergalhão.

\section{b) Estudo em modelo reduzido}

Com intuito de constatar os estudos de simulação foram enterradas em areia cinco barras de ferro com diâmetros diferentes e foram realizados ensaios com o radar colocado na superfície usando antena de $1 \mathrm{GHz}$. As Fotos 1 e 2 mostram o experimento e as Figuras 7 e 8 apresentam os resultados. 


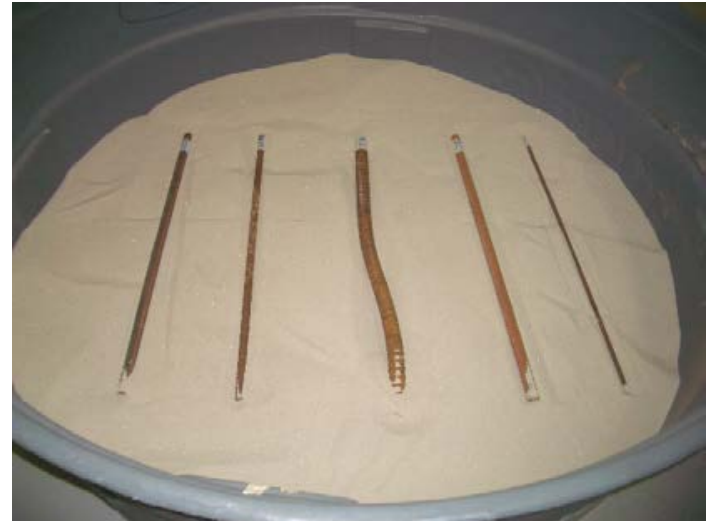

Foto 1. Vergalhões de diferentes bitolas que foram enterrados em areia.

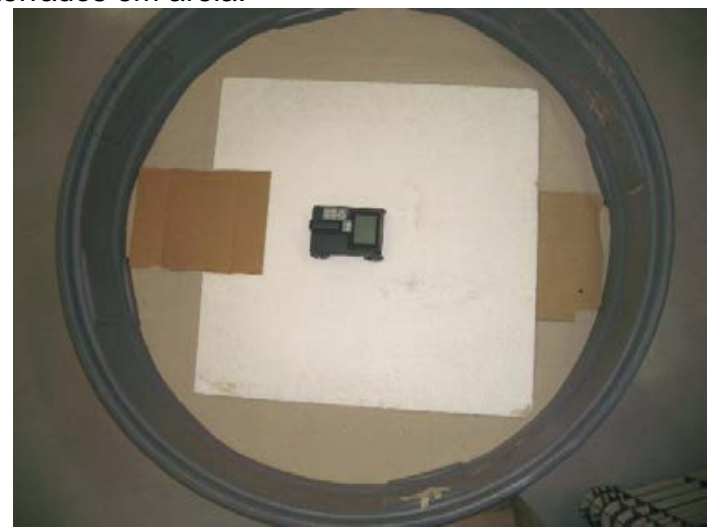

Foto 2. GPR passando sobre vergalhões enterrados na areia.

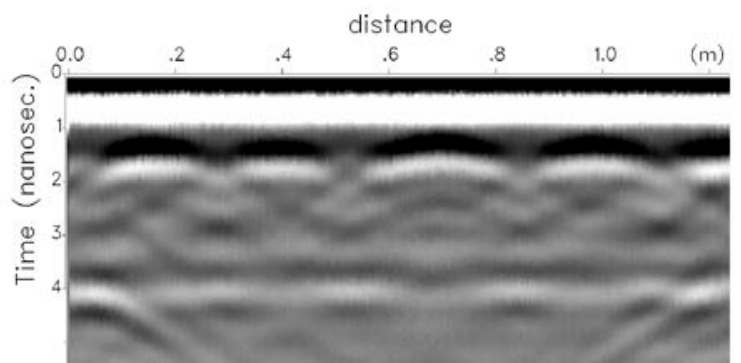

Figura 7. Seção de radar obtida com antena de $1 \mathrm{GHz}$ sobre cinco vergalhões de ferro enterrados em areia a uma mesma profundidade.

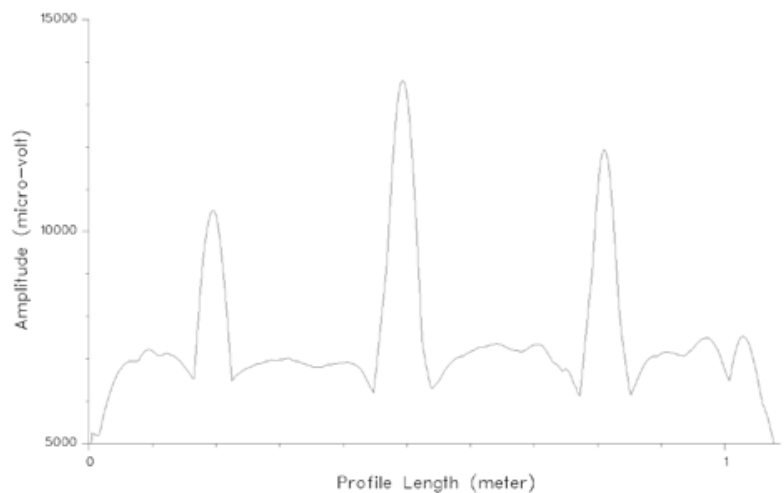

Figura 8. Gráfico da amplitude do sinal de radar da seção obtida com antena de $1 \mathrm{GHz}$ sobre três dos vergalhões de ferro enterrados em areia a uma mesma profundidade. Os picos de amplitude coincidem com a localização dos vergalhões e quanto maior o diâmetro do vergalhão maior a amplitude.

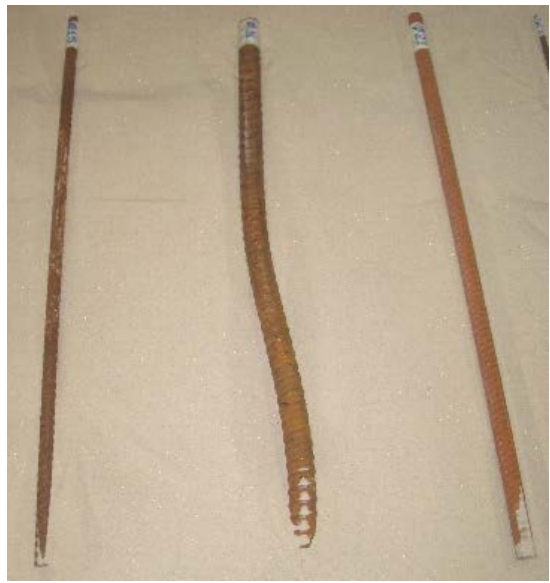

Foto 3. Os três vergalhões que geraram o perfil da Figura 8.

\section{c) Aplicação em estrutura de concreto}

Usando uma antena de $1.6 \mathrm{GHz}$, foi realizado um levantamento com radar sobre a laje de uma estrutura de concreto situada no IPT. O espaçamento entre os registros foi de $2,5 \mathrm{~mm}$.

A Foto 4 ilustra a aquisição dos dados, a Figura 9 apresenta uma das seções de radar com as anomalias observadas e a Figura 10 mostra o gráfico da amplitude do sinal de radar em função da distância. 


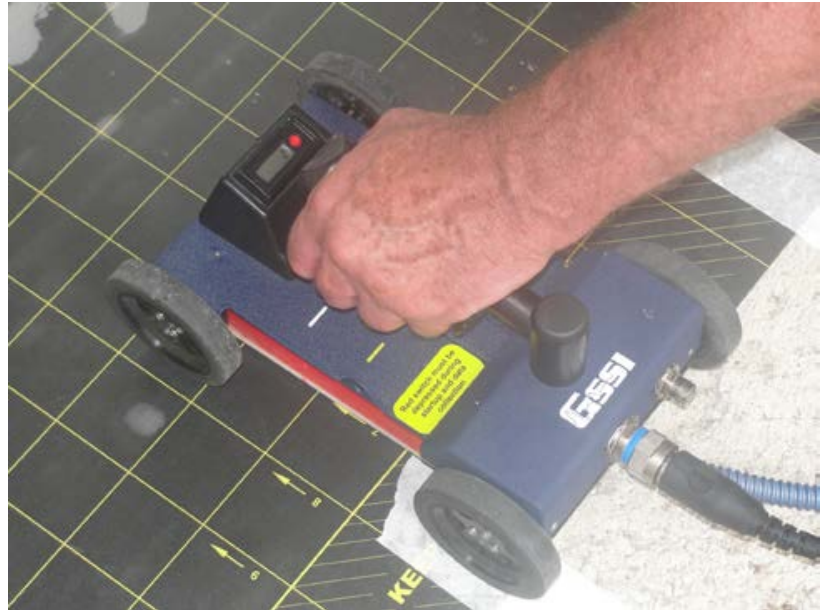

Foto 4. Ensaio com radar sobre a laje da estrutura.

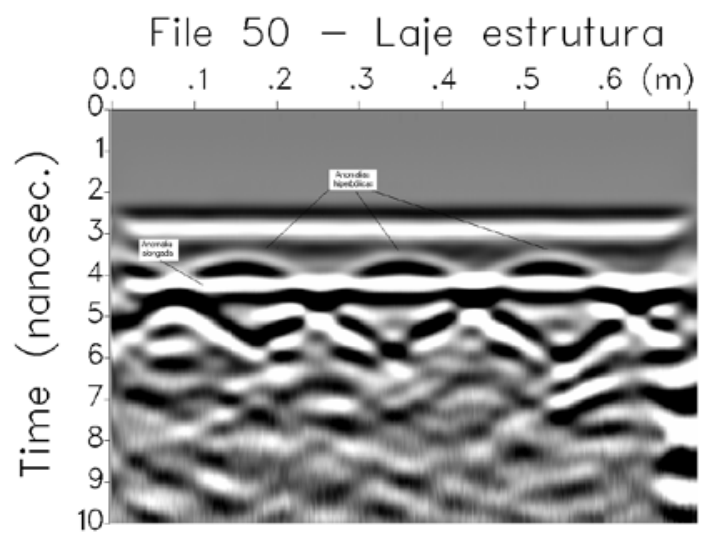

Figura 9. Uma das seções de radar realizada sobre a laje de concreto da estrutura.

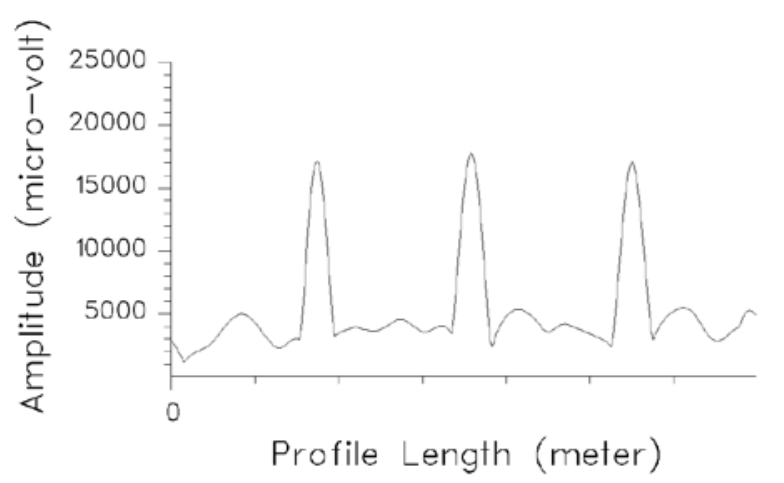

Figura 10. Gráfico da amplitude do sinal de radar em função da distância para a seção 50 de radar realizada sobre a laje de concreto.

As três anomalias hiperbólicas observadas na seção de radar da Figura 9 foram associadas a vergalhões situados a uma mesma profundidade e por possuírem amplitudes de valores semelhantes, podem apresentar o mesmo diâmetro.
A laje de concreto foi quebrada e pôde-se constatar a presença de três vergalhões situados a mesma profundidade e posuindo a mesma bitola como mostrado na Foto 5.

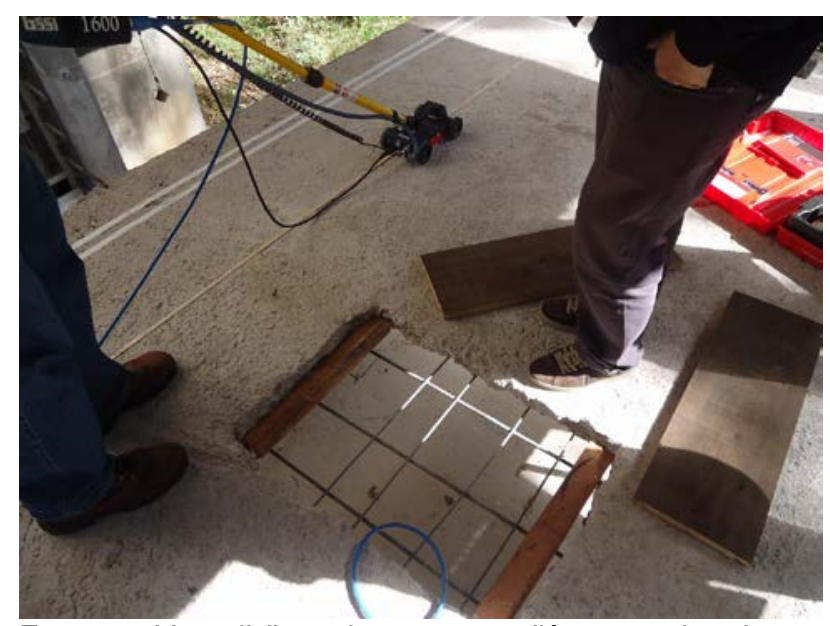

Foto 5. Vergalhões de mesmo diâmetro situados a mesma profundidade existentes na laje da estrutura de concreto que foram identificados com o radar.

\section{Considerações Finais}

Os resultados obtidos neste trabalho por meio de simulação teórica, ensaios em modelos reduzidos e aplicação prática em estruturas de concreto mostraram que:

a) A anomalia de radar produzida por vergalhão de aço inserido no concreto é de forma hiperbólica cujo ápice indica a posição do vergalhão.

b) A forma da hipérbole não muda significativamente com o diâmetro do vergalhão. Isto significa que qualquer vergalhão de diâmetro menor que 2" produzirá hipérbole do mesmo tamanho e de mesma forma.

c) Para vergalhões localizados numa mesma profundidade, quanto maior o diâmetro da barra, maior será a amplitude do sinal.

d) Quanto mais profundo estiver o vergalhão, menor será a amplitude do sinal, o que impossibilita identificar o diâmetro do vergalhão por meio de amplitude.

O ensaio geofísico com radar fornece informações precisas sobre a localização de armaduras de aço em concreto e embora não seja possível identificar o diâmetro do vergalhão com essa técnica, pode-se saber se um vergalhão é mais grosso ou mais fino que outro situado na mesma profundidade, por meio da amplitude do sinal de radar.

Essa técnica geofísica pode ser uma boa opção na escolha entre as diferentes técnicas não destrutivas de investigação de armaduras e cabos de protensão, utilizadas para os propósitos de reforço e recuperação de viadutos, pontes e estruturas de concreto. 


\section{Referências}

Giannopoulos, A. (2005) GPRMAX2D/3D Electromagnetic simulator for Ground Penetrating Radar - version 2.0 - User's Manual, D.Phil thesis. Department of Electronics, University of York, UK.

MALA, GeoScience (1995). RADPRO - Radar Processing Software for RAMAC/GPR - Ver. 2.2 User's Manual. KIGAM Geophysical Research Div.

Sandmeier, K.J. (2008) Reflex2DQuick - Program for processing of electromagnetic reflection, refraction and transmission data - version 1.2.1. Germany. 